\title{
Analysis and Visualisation of Research Trends in Carbon Nano Tubes: A General Review
}

\section{Raman Kumar'}

${ }^{1}$ Department of Mechanical Engineering Chandigarh University, Gharuan, Mohali, Punjab, 140413

Article History: Received: 11 January 2021; Accepted: 27 February 2021; Published online: 5 April 2021

\begin{abstract}
Carbon nanotubes are made up of carbon atoms, with each carbon atom covalently bonded to three other carbon atoms. The bibliometric analysis had been conducted to understand the active authors, organizations, journals, and countries involved in the research domain of "Carbon Nanotubes". All published articles related to "Carbon Nanotubes" from "Scopus", were analyzed using the VOS viewer to develop analysis tables and visualization maps. This article had set the objective to consolidate the scientific literature regarding the "Carbon Nanotubes"and also to find out the trends related to the same.The most active journals in this research domain were Journal of Computational and Theoretical Nano Science; Journal of Physical Society of Japan and Journal of Power Sourceswith the highest publications, citations, and co-authorship links. The most active countries were India and Japan. The leading organizations were the Chinese Academy of Sciences, China, and the Islamic Azad University of Iran.The most active authors who had made valuable contributions related to Nanomaterial were Li X, Ajiki H, and Ando T.
\end{abstract}

Keywords:Carbon Nanotubes,Bibliometric analysis, VOS viewer,

\section{Introduction}

Nanotechnology and Nanomaterials had revolutionized the production, manufacturing, and construction sectors across the globe. Nanomaterials are the material possessing a minimum, one external dimension measuring 1-100nm. Carbon Nanotubes (CNTs), also called "bucky tubes" was an innovative product based on Nanotechnology, discovered in 1991[1].Carbon nanotubes are made up of carbon atoms, with each carbon atom covalently bonded to three other carbon atoms. CNTs would be in the shape of cylinders. Carbon nanotubes have diameters as small as $1 \mathrm{~nm}$ and lengths up to several centimeters. CNTs can be either single-walled or multiwalled. A single-walled CNT would have a diameter less than 1nm and a multi-walled CNT would have a diameter of more than 100nm[2], [3]. CNTs had the features of high strength, lightweight, high thermal, and electric conductive properties. Nanocarbon tubes have some disadvantages and the main disadvantage is connected with health, as some studies pointed out the health hazards of using Nanocarbon tubes [4]. CNT has some toxic properties and further research is required to get a holistic picture regarding human safety in using CNTs.

1.1 Research Objectives

a) To consolidate the literature regarding the Carbon Nanotubes

b) To find out the trends related to research in the Carbon Nanotubes

The following research questions are framed for conducting bibliometric analysis systematically.

1.2 Research Questions

a) Who are the active researchers working on the Carbon Nanotubes?

b) Which are the main organizations and countries working on Carbon Nanotubes?

c) Which are the main journals related to Carbon Nanotubes?

\subsection{Significance of this research}

Carbon Nanotubes is an important research niche in material engineering. This article points out the need for future research regarding Nanotechnology andCarbon Nanotubes[5]. This bibliometric analysis will be a useful platform for future researchers by realizing the top researchers, organizations, and countries involved in research regardingCarbon Nanotubes. This bibliometric article is arranged in four sections. The first section is the introduction, followed by the discussion of the methodology by which the research was conducted. The third section deals with results and discussion. The fourth section deals with the conclusion.

\section{Research Methodology}


Scopus files had been used for this article. For the article selection, the Boolean used was TITLE ("Carbon Nanotubes") on 04/01/2020. All the tables in this paper were created by using Microsoft Excel and VOS Viewer. Grammarly was used for spelling and grammar checks. Mendeley was used for article review and citation. This paper had been inspired by bibliometric analysis in its presentation style, analysis, and methodology from the works.[6]-[8]

\section{Results and discussion}

3.1 Results

This first round of search produced an outcome of 577 documents, insevenlanguages, out of which 517 documents were in English. The classification of document categories is shown in Figure 1. For improving the quality of the analysis, we had selected only the peer-reviewed articles and all other documents had not been considered. Thus after using filters "Article"and "English" the second round search produced an outcome of 296 English articles (both open access and others) andhad been used to conduct bibliometric analysis and visualization using VOS Viewer. The English research articles in this domain since 1992 had been shown in Figure 2 .

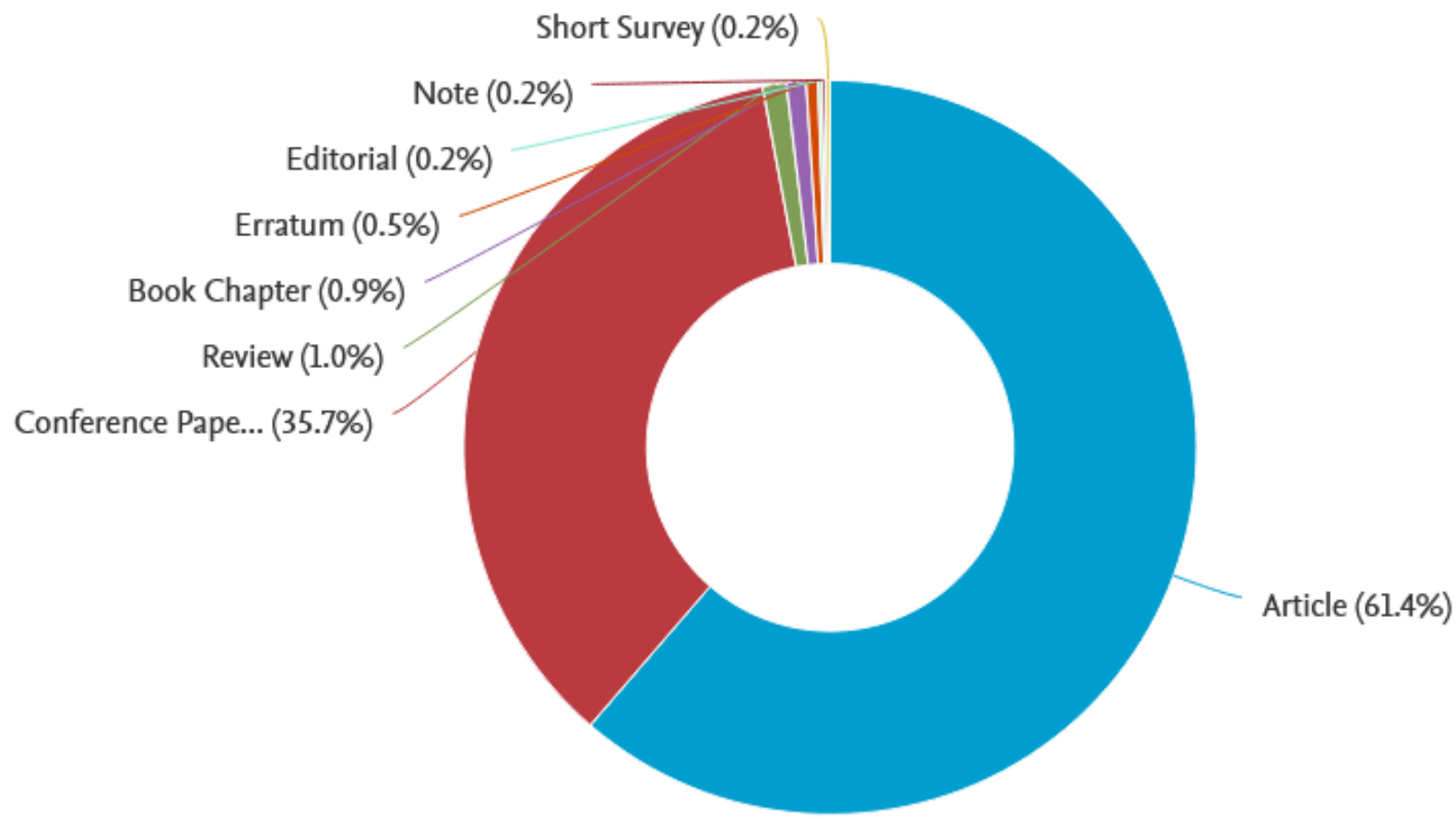

Figure 1: Classification of the documents on "Carbon Nanotubes", Source: www.scopus.com

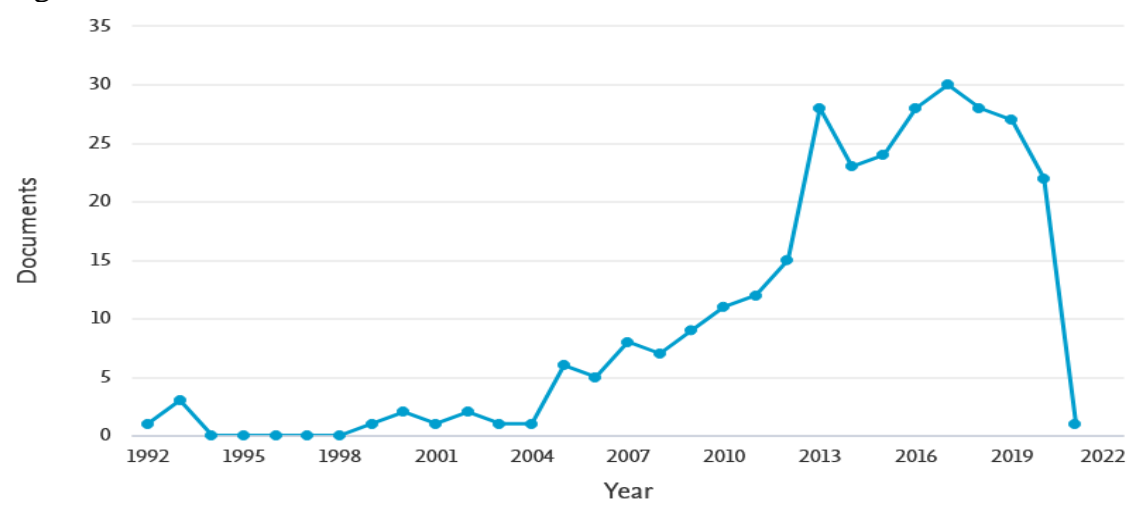

Figure 2: Period wise publication of articles, Source: WWW.scopus.com

Co-authorship analysis of top authors had been shown in figure 3. For a better presentation of the analysis, the parameters used were the minimum number of documents of an author as threeand the minimum number of citations of authors as one. This combination plotted the map of 30 authors, in 10 clusters. The overlay visualization map of co-authorship analysis plotted in Figure 3, points out the major researchers with their strong co-authorship linkages and clusters involved. 


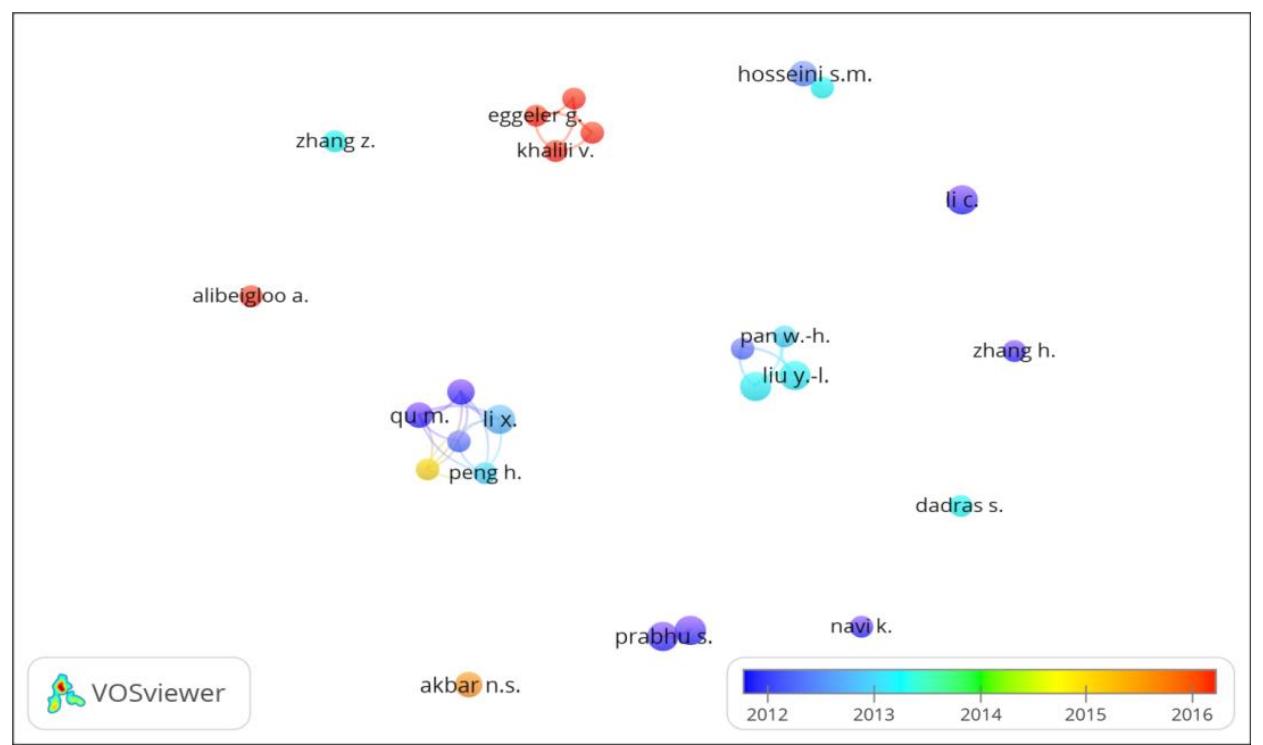

Figure 3: Co-authorship analysis on basis of authors

The citation analysis of top authors had been shown in table 1, along with co-authorship links.For the citation analysis, the parameters used werethe minimum number of documents of an author as one and the minimum citations of an author as one.

Table 1: Highlights of most active authors

\begin{tabular}{|c|c|c|c|c|c|}
\hline Description & Authors & $\begin{array}{l}\text { Documen } \\
\text { ts }\end{array}$ & ns ${ }^{2}$ Citatio & \begin{tabular}{l}
\multicolumn{2}{c}{ Average } \\
citations per \\
documents
\end{tabular} & $\begin{array}{r}\text { Link } \\
\text { strength }\end{array}$ \\
\hline $\begin{array}{l}\text { Authors with the } \\
\text { highest publication co- } \\
\text { authorship links }\end{array}$ & Li X & 5 & 235 & 47 & 29 \\
\hline Authors with the & Ajiki H & 1 & 605 & 605 & 1 \\
\hline highest citation & Ando $\mathrm{T}$ & 1 & 605 & 605 & 1 \\
\hline
\end{tabular}

In Co-occurrence analysis, we had used all keyword analyses, by keeping the minimum number of occurrences of a keyword as10. This combination plotted the map of 31thresholds, in fiveclusters. The overlay visualization of co-occurrence analysis of keywords has been shown in Figure 4.

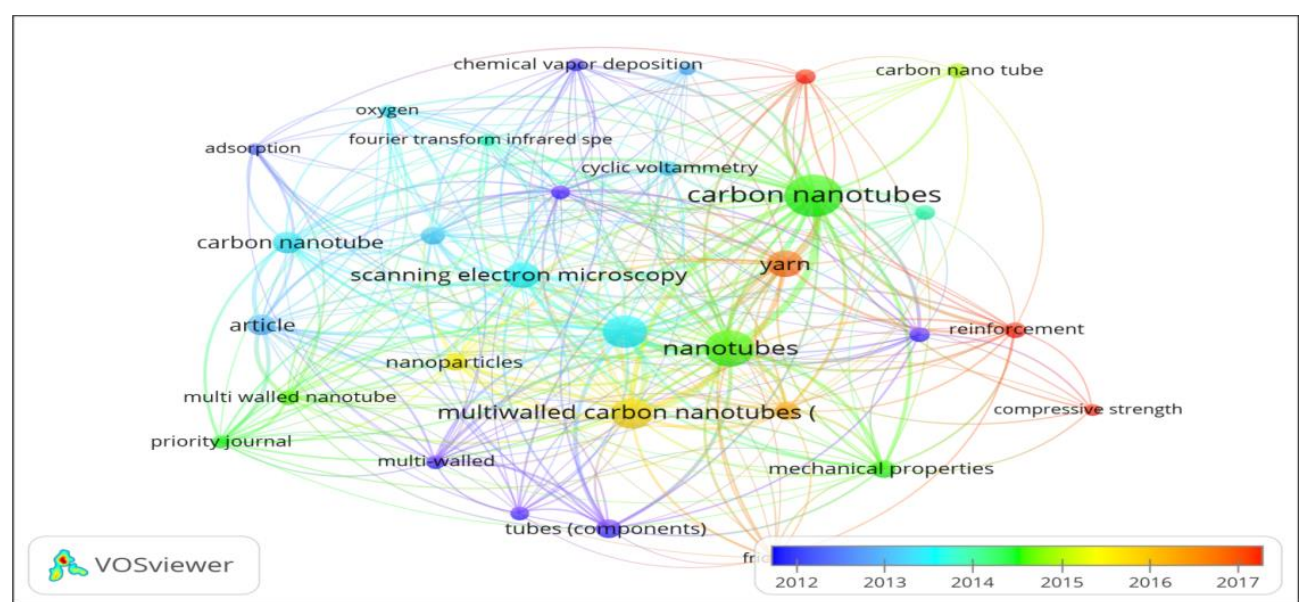

Figure 4: Co-occurrence analysis on basis of all keywords

The leadingorganizations engaged in research on "Carbon Nanotubes" had been found out by the volume of publications and citation analysis, the parameters used are the minimum number of documents of an organization as one and the minimum number of citations of organizations as one. This combination plotted the map of 462organizations, in 229clusters. 
The leading organization in the research regarding "Carbon Nanotubes", with the highest number of publications and citations, were the Chinese Academy of Sciences of Chinaand the Islamic Azad University of Iran(Refer to table 2).

Table 2: Highlights of the most active organization

\begin{tabular}{|l|c|c|c|c|}
\hline Organizations & Country & Documents & Citatio & $\begin{array}{c}\text { Average } \\
\text { Citations } \\
\text { document }\end{array}$ \\
\hline per \\
Chinese Academy of Sciences & China & 8 & 276 & 34.5 \\
\hline Islamic Azad University & Iran & 10 & 56 & 5.6 \\
\hline
\end{tabular}

Co-authorship analysis of the countries engaged in the research on "Carbon Nanotubes" had been shown in Figure 5. For a better presentation of the analysis, the parameters used were the minimum number of documents of an author as three and the minimum number of citations of authors as one. This combination plotted the map of 18 countries, sevenclusters. The overlay visualization map of co-authorship analysis plotted in Figure 5, points out the main countries with their strong co-authorship linkages and clusters involved.

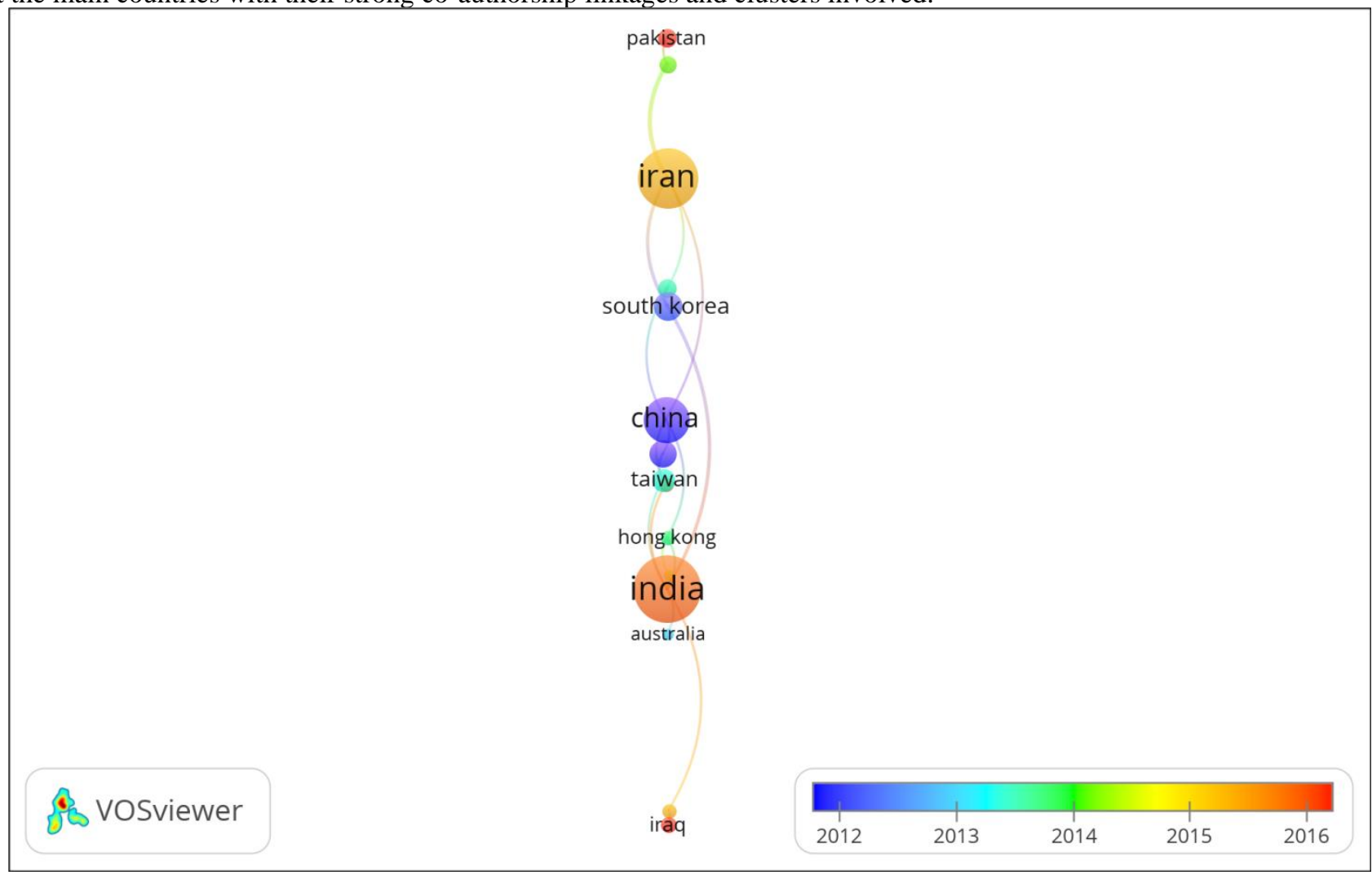

Figure 5: Co-authorship analysis on basis of countries

The citation analysis of top countries had been shown in table 3, along with co-authorship links. For the citation analysis, the parameters used were the minimum number of documents of acountry as one and the minimum citations of the country as one.

Table 3: Highlights of Active Countries

\begin{tabular}{|c|r|r|r|r|r|}
\hline Description & Country & ts Documen & Citatio & \multicolumn{1}{|c|}{$\begin{array}{c}\text { Average } \\
\text { citations } \\
\text { documents }\end{array}$} & $\begin{array}{c}\text { Link } \\
\text { per }\end{array}$ \\
\hline $\begin{array}{l}\text { The coungth with the } \\
\text { highest publication and co- } \\
\text { authorship links }\end{array}$ & India & 89 & 813 & & \\
\end{tabular}




\begin{tabular}{|c|r|r|r|r|r|}
\hline $\begin{array}{c}\text { The country with the } \\
\text { highest citation }\end{array}$ & Japan & 15 & 1103 & & 73.5 \\
\hline
\end{tabular}

The most active countries in this research domain were India andJapan with the highest number ofpublications, citations, and co-authorship links.

1.

2. Link analysis and citation analysis were used to identify the most active journal in this research domain. We have take the minimum number of documents of a journal as one and the minimum number of citations of a journal as one for $t$ citation analysis. Highlights of the most active and relevant journals related to the "Carbon Nanotubes"are shown in tal the journal activity of this research domain through parameters of publication volume, citations, and co-authorship Computational and Theoretical Nano Science; Journal of Physical Society of Japan and Journal of Power Sourcesw journal with the highest publications, citations, and co-authorship links respectively.

3. Table 4: Analysis of journal activity

\begin{tabular}{|c|c|c|c|c|}
\hline 4. Description & $\begin{array}{l}\text { 5. Journal } \\
\text { details }\end{array}$ & 6. Documents & 7. Citations & $\begin{array}{l}\text { 8. Average } \\
\text { citations per } \\
\text { documents }\end{array}$ \\
\hline $\begin{array}{l}\text { 10. Journal with the } \\
\text { highest } \\
\text { publications }\end{array}$ & $\begin{array}{l}\text { 11. Journal of } \\
\text { Computatio } \\
\text { nal and } \\
\text { Theoretical } \\
\text { Nano } \\
\text { Science }\end{array}$ & 12. 7 & 13. 59 & 14. 8.4 \\
\hline $\begin{array}{l}\text { 16. Journal with the } \\
\text { highest citation }\end{array}$ & $\begin{array}{l}\text { 17. Journal of } \\
\text { Physical } \\
\text { Society of } \\
\text { Japan } \\
\end{array}$ & 18. 1 & 19. 605 & 20. 605 \\
\hline $\begin{array}{l}\text { 22. Journal with the } \\
\text { highest co- } \\
\text { authorship links }\end{array}$ & $\begin{array}{l}\text { 23. Journal of } \\
\text { Power } \\
\text { Sources }\end{array}$ & 24. 6 & 25. 240 & 26. 40 \\
\hline
\end{tabular}

28. From the above discussion regarding the bibliometric patterns in the research regarding the Carbon Nanotubes,this rese gradual increase in research interest regarding the Carbon Nanotubes from the starting of the millennium and the mor positively.This points out the relevance and potential of this research domain (Refer to Figure 2). The most active auth domainwereLi X, Ajiki H, and Ando T. with the highest publication, citations, and co-authorship links (Refer to t: analysis of top countries researching Carbon Nanotubes[9]-[11]indicates that India and Japanwere the leading co regarding Carbon Nanotubes (Refer to figure 5). The top journals of this research domain were identified as Journal of Theoretical Nano Science; Journal of Physical Society of Japan and Journal of Power Sources with the highest publica co-authorship links. Fromthese wide sources of information, researchers can focus on top journals where they can identiand highly cited articles regarding Carbon Nanotubes.

\section{Conclusion}

30. The Carbon Nanotubesis an interesting research domain and the most active journals related to this research doma Computational and Theoretical Nano Science; Journal of Physical Society of Japan and Journal of Power Source publications, citations, and co-authorship links. The most active countrieswere India and Japan. The leading organizat research regarding Carbon Nanotubeswerethe Chinese Academy of Sciences, China, and the Islamic Azad Universit active authors who had made valuable contributions related to Carbon Nanotubeswere Li X, Ajiki H, and Ando T.Tl offers a new avenue for researchers, and the future research can be on Carbon Nanotubes and techniques and systems.

\section{References}

32. A. Ur Rehman, R. Mehmood, S. Nadeem, N. S. Akbar, and S. S. Motsa, "Effects of single and multi-walled carbon nano engine oil based rotating fluids with internal heating," Adv. Powder Technol., vol. 28, no. 9, pp. 1991-2002, 2017.

33. S.-F. Zheng, J.-S. Hu, L.-S. Zhong, W.-G. Song, L.-J. Wan, and Y.-G. Guo, "Introducing dual functional CNT nanomicrospheres toward superior electrode materials for lithium-ion batteries," Chem. Mater., vol. 20, no. 11, pp. 3617

34. M. Jayalakshmi, M. M. Rao, N. Venugopal, and K.-B. Kim, "Hydrothermal synthesis of SnO2-V2O5 mixed oxide screening of carbon nano-tubes (CNT), V2O5, V2O5-CNT, and SnO2-V2O5-CNT electrodes for supercapacitor app Sources, vol. 166, no. 2, pp. 578-583, 2007.

35. K. M. Batoo et al., "Structural, morphological and electrical properties of $\mathrm{Cd} 2+\mathrm{doped} \mathrm{MgFe} 2-\mathrm{xO} 4$ ferrite nanoparticles, 
vol. 726, pp. 179-186, 2017.

36. P. Gairola, S. P. Gairola, V. Kumar, K. Singh, and S. K. Dhawan, "Barium ferrite and graphite integrated with polyanilin against electromagnetic interference," Synth. Met., vol. 221, pp. 326-331, 2016.

37. S. Dhar, Z. Liu, J. Thomale, H. Dai, and S. J. Lippard, "Targeted single-wall carbon nanotube-mediated Pt(IV) prodrug as a homing device," J. Am. Chem. Soc., vol. 130, no. 34, pp. 11467-11476, 2008.

38. H. Wu, G. Zheng, N. Liu, T. J. Carney, Y. Yang, and Y. Cui, "Engineering empty space between Si nanoparticles for anodes," Nano Lett., vol. 12, no. 2, pp. 904-909, 2012.

39. M. Whitby and N. Quirke, "Fluid flow in carbon nanotubes and nanopipes," Nat. Nanotechnol., vol. 2, no. 2, pp. 87-94,

40. S. Guo et al., "Phosphorus-Doped Carbon Nitride Tubes with a Layered Micro-nanostructure for Enhanced VisibleHydrogen Evolution," Angew. Chemie - Int. Ed., vol. 55, no. 5, pp. 1830-1834, 2016.

41. T. Zhang, S. Mubeen, N. V Myung, and M. A. Deshusses, "Recent progress in carbon nanotube-based

42. S. Y. Set, H. Yaguchi, Y. Tanaka, and M. Jablonski, "Laser Mode Locking Using a Saturable Absorber Incorporating J. Light. Technol., vol. 22, no. 1, pp. 51-56, 2004. 